\title{
Direct Detection of Benzene, Toluene, and Ethylbenzene at Trace Levels in Ambient Air by Atmospheric Pressure Chemical Ionization Using a Handheld Mass Spectrometer
}

\author{
Guangming Huang, ${ }^{\mathrm{a}}$ Liang Gao, ${ }^{\mathrm{a}}$ Jason Duncan, ${ }^{\mathrm{a}}$ Jason D. Harper, ${ }^{\mathrm{a}}$ \\ Nathaniel L. Sanders, ${ }^{a}$ Zheng Ouyang, ${ }^{b}$ and R. Graham Cooks ${ }^{a}$ \\ a Department of Chemistry and Center for Analytical Instrumentation Development, Purdue University, \\ West Lafayette, Indiana, USA \\ ${ }^{\mathrm{b}}$ Weldon School of Biomedical Engineering, Purdue University, West Lafayette, Indiana, USA
}

\begin{abstract}
The capabilities of a portable mass spectrometer for real-time monitoring of trace levels of benzene, toluene, and ethylbenzene in air are illustrated. An atmospheric pressure interface was built to implement atmospheric pressure chemical ionization for direct analysis of gas-phase samples on a previously described miniature mass spectrometer (Gao et al. Anal. Chem. 2006, 78, 5994-6002). Linear dynamic ranges, limits of detection and other analytical figures of merit were evaluated: for benzene, a limit of detection of 0.2 parts-per-billion was achieved for air samples without any sample preconcentration. The corresponding limits of detection for toluene and ethylbenzene were 0.5 parts-per-billion and 0.7 parts-per-billion, respectively. These detection limits are well below the compounds' permissible exposure levels, even in the presence of added complex mixtures of organics at levels exceeding the parts-per-million level. The linear dynamic ranges of benzene, toluene, and ethylbenzene are limited to approximately two orders of magnitude by saturation of the detection electronics. (J Am Soc Mass Spectrom 2010, 21, 132-135) (c) 2010 American Society for Mass Spectrometry
\end{abstract}

$\mathrm{D}$ emand for in situ analysis of trace levels of environmental chemicals is increasing. For example, the aromatic hydrocarbon benzene has been linked to adverse health effects, particularly leukemia, plastic anemia, and bone-marrow disorders in humans, even at low doses [1-3]. The permissible exposure limit (PEL) [4] for benzene vapor in the United States is 1 part-per-million (ppm) as set by OSHA [5] and $0.1 \mathrm{ppm}$ as set by NIOSH [6]. The European Union has established a stricter limit for benzene of $5 \mu \mathrm{g} / \mathrm{m}^{3}$ [ $\sim 1.44$ parts-perbillion (ppb)] taking effect in 2010 [7]. Hence, the desirability of identifying toxic compounds in situ is widely appreciated [8-10]. Among the various techniques developed for monitoring trace levels of chemicals in air are many based on solid-phase extraction (SPE) or solid-phase microextraction (SPME) [11, 12], with recovery of the preconcentrated compounds by solvent or thermal desorption and qualitative or quantitative analysis by gas chromatography/mass spectrometry (GC/MS) [13-16]. Whilst these methods achieve high specificity and sensitivity, the need for preconcentration over long periods

Address reprint requests to Professor R. G. Cooks, Department of Chemistry, Purdue University, 560 Oval Drive, West Lafayette, IN, USA. Professor Z. Ouyang, Weldon School of Biomedical Engineering, Purdue University, 206 South Intramural Drive, West Lafayette, IN, USA. E-mail: cooks@purdue.edu and E-mail: ouyang@purdue.edu precludes instant on-site monitoring. Hence, there is a continuing interest in the development of analytical procedures for measuring the concentrations of specific chemicals in ambient air rapidly and accurately when such information is immediately required.

Portable mass spectrometers have long been considered as potential candidates to meet the above demands. For example, SCIEX triple quadrupoles were introduced in the 1980s to address this very problem, e.g., the Mississauga disaster was monitored in this way [17], although these successful systems were transportable, not portable $[18,19]$. Several versions of portable mass spectrometers have been used for in situ gasphase chemical analysis [20, 21] based on selective membrane sampling [22-25]. A related sorbent introduction system using preconcentration in a solid matrix and thermal release was employed to achieve trace level detection of benzene with the handheld Mini 10.5 [26]. These successful methods still require some time (usually tens of seconds) for preconcentration but the emergence of simple ambient ionization methods [27, 28] could avoid the necessity for any sample pretreatment; when coupled with a miniature mass spectrometer, this combination should allow in situ, and virtually instantaneous, analysis. The performance of such a system in 
direct air analysis remains to be determined, and that task is undertaken in this study.

We report the combination of atmospheric pressure chemical ionization (APCI) and a miniature mass spectrometer for the monitoring of benzene, toluene, and ethylbenzene at trace levels in ambient air. The ability to sample air directly via an atmospheric pressure inlet and to ionize it by APCI is ideal for portable instrumentation aimed at real-time trace analysis. In this study, as little as $0.2 \mathrm{ppb}$ benzene in ambient air could be directly detected without sample preconcentration.

\section{Experimental}

A previously described handheld rectilinear ion trap mass spectrometer (known as the Mini 10.5) [29] was used for the experiments reported in this article. All MS conditions are the same as reported previously unless noted [29]. APCI ion source was fashioned from the easily-machined thermoplastic polyether ether ketone (PEEK) [30, 31]. A diagram of the APCI/Mini 10.5 is illustrated as Figure 1a.

Benzene, toluene, ethylbenzene, and other chemicals were all obtained from Sigma-Aldrich Corp. (Milwaukee, WI, USA) and used without further purification. A sample preparation and introduction system was used to provide for gaseous samples vapors from the saturated headspace of a pure liquid analyte. (See Supple- mentary Materials, which can be found in the electronic version of this article, for a detailed description of the miniature mass spectrometer, the APCI ion source and vapor sampling system).

\section{Results and Discussion}

\section{Direct Detection of Chemicals in Ambient Air at Trace Levels}

Using the APCI/Mini 10.5 system (Figure 1a), benzene, toluene, and ethylbenzene were analyzed at concentrations corresponding to their particular limits of detection (LOD), then each concentration was increased gradually until the point at which the calibration curve became nonlinear, thereby establishing the linear dynamic range of each compound. Direct detection of benzene at sub-PEL levels was successful using APCI as shown in Figure 1b. Under APCI conditions, neutral benzene undergoes simple charge transfer with reagent ions (ionized components of air) to produce the molecular ion $(\mathrm{m} / \mathrm{z})$ [32]. The LOD for benzene was determined to be $0.2 \mathrm{ppb}$ (Table 1 ). Figure $1 \mathrm{~b}$ shows a typical mass spectrum at a concentration of $15 \mathrm{ppb}$. In the cases of toluene and ethylbenzene, the fragment ions $\mathrm{m} / \mathrm{z} 91$ and 105 were the main ions observed in the APCI mass spectra. The mass spectra of these two analytes at concentrations of 35 and $60 \mathrm{ppb}$ are shown in Figure 1b,
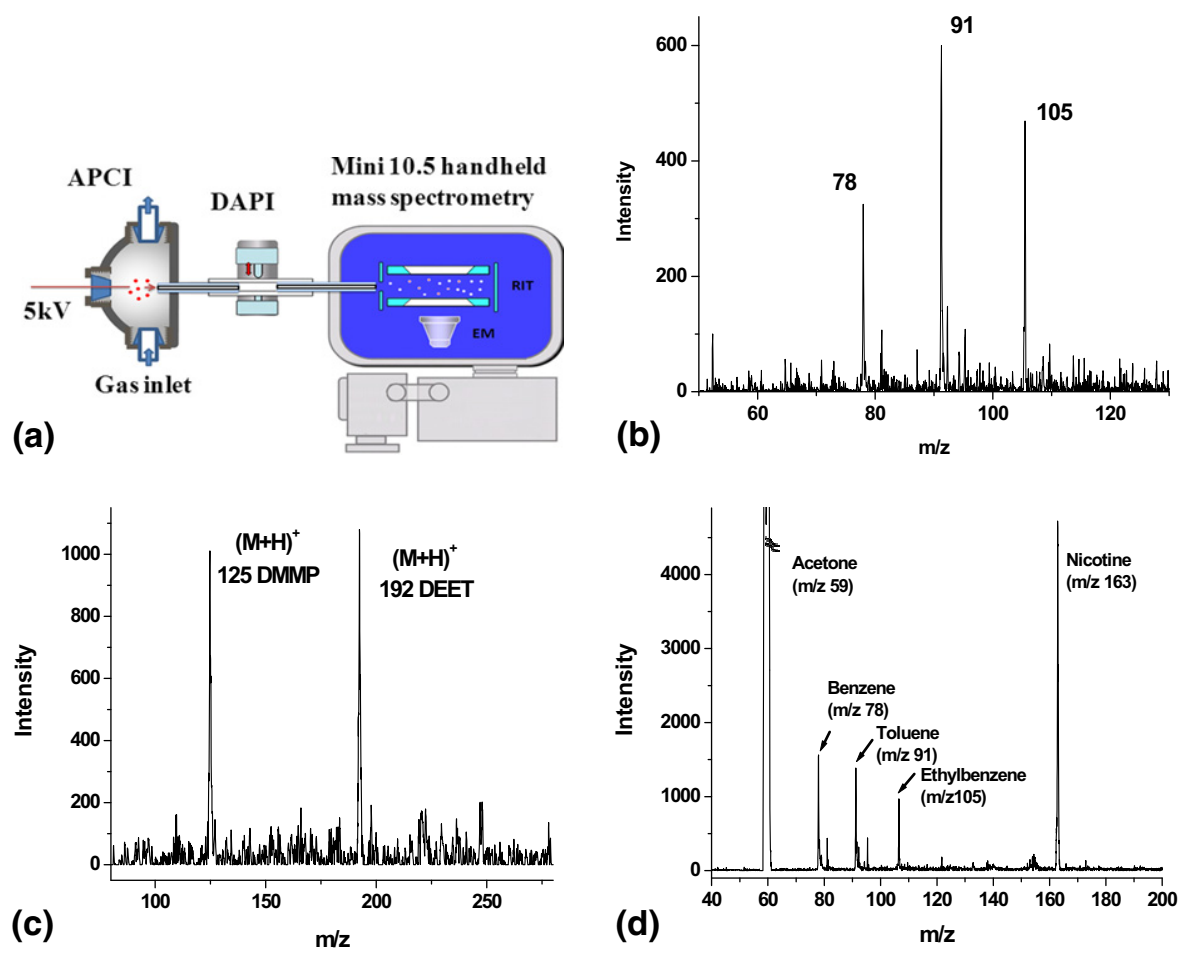

Figure 1. (a) Diagram of APCI/Mini 10.5. (b) Typical mass spectrum of mixture of benzene (15 ppb), toluene (35 ppb), and ethylbenzene (60 ppb). (c) Typical mass spectrum of DMMP (65 ppb) and DEET $(260 \mathrm{ppb})$ obtained using the APCI/Mini 10.5. (d) Typical mass spectrum using APCI/Mini 10.5 for benzene (125 ppb), toluene (150 ppb), and ethylbenzene (210 ppb) in the presence of $0.1 \%$ acetone and $500 \mathrm{ppb}$ nicotine in air. (Resolution at the scan speed used is insufficient to resolve ${ }^{13} \mathrm{C}$ isotopes). 
Table 1. Analytical performance of the APCI/Mini 10.5

\begin{tabular}{lccrr}
\hline \multicolumn{1}{c}{ Chemical } & $\begin{array}{c}\text { Monitored } \\
\text { ion }(\mathrm{m} / \mathrm{z})\end{array}$ & $\begin{array}{c}\text { Linear dynamic } \\
\text { range }\end{array}$ & LOD $^{\mathrm{a}}$ & $\begin{array}{r}\text { RSD } \\
(\%)^{\mathrm{b}}\end{array}$ \\
\hline \hline Benzene & 78 & $0.6-240 \mathrm{ppb}$ & $0.2 \mathrm{ppb}$ & $8.5 \%$ \\
Toluene & 91 & $1-330 \mathrm{ppb}$ & $0.5 \mathrm{ppb}$ & $7.6 \%$ \\
Ethylbenzene & 105 & $1.5-800 \mathrm{ppb}$ & $0.7 \mathrm{ppb}$ & $12.4 \%$ \\
DEET & 192 & $2-1000 \mathrm{ppb}$ & $1 \mathrm{ppb}$ & $9.2 \%$ \\
DMMP & 125 & $1-250 \mathrm{ppb}$ & $0.5 \mathrm{ppb}$ & $11.3 \%$
\end{tabular}

a Limit of detection (at S/N 3).

${ }^{\text {b }}$ Relative standard deviation (RSD) of 7 replicated measurements at the concentration of $10 \mathrm{ppb}$.

which illustrates the simultaneous detection for benzene, toluene, and ethylbenzene using APCI/Mini 10.5. The sensitivity achieved is well above that required to reach the established U.S. permissible exposure limits (PELs), as well as the European limits [7], with linear ranges of approximately two orders of magnitude (Table 1).

To extend the enquiry into the performance of this system for the direct analysis of small organics in air, dimethylmethylphosphonate (DMMP) and $\mathrm{N}, \mathrm{N}-$ diethylmetatoluamide (DEET) were chosen as representative compounds and examined directly in air. Selected amounts of DMMP and DEET were added to achieve specific concentrations of the vapors in ambient air. As shown in Figure 1c, protonated molecules were detected for both DEET and DMMP at $\mathrm{m} / \mathrm{z}$ of 192 and 125, respectively, at concentrations as low as 65 and 260ppb.

\section{Optimization of Experimental Conditions}

Benzene at a concentration of $10 \mathrm{ppb}$ was chosen for experiments in which experimental conditions were optimized. The effect of the relative humidity of air on the ion intensity was studied given that relative humidity will vary in field analyses. The initial relative humidity was set to around 5\% and gradually raised to 90\%. As illustrated in Figure 2a, lower humidities give inherently higher ion intensities. When the humidity is too high, high quality data can be recorded only if one passes the air through a drying tube $(1 / 8$ in. i.d. and 15 $\mathrm{cm}$ long, filled with dried $\mathrm{CaCl}_{2}$ ), preferably to achieve a finial relative humidity less than $10 \%$. The effect of the air flow rates in the range of 0.5 to $5 \mathrm{~L} / \mathrm{min}$ were also investigated (Figure 2a). The ion intensity increases with flow rate except that above $2 \mathrm{~L} / \mathrm{min}$ the intensity remained relatively constant. However, as the method was developed for a handheld MS instrument, the power consumption required has to be considered. Now, a small sample pump (model: NMP015M; KNF Neuberger, Trenton, NJ, USA) is used for the Mini-MS system, which can provide a maximum flow rate of 2.5 $\mathrm{L} / \mathrm{min}$; this flow rate was chosen to provide enough sensitivity as well as minimize the power consumption. The optimized discharge voltage for the corona APCI source was chosen as $5 \mathrm{kV}$ (Figure $2 \mathrm{~b}$ ). The pinch valve open time was optimized as $13 \mathrm{~ms}$.
Other parameters were also optimized. Multiplier voltage was set as $1800 \mathrm{~V}$ to obtain the highest signal/ noise ratio. Ejection AC frequency was set as $400 \mathrm{kHz}$ and the $\mathrm{AC}$ voltage was in the range $0.5-1.2 \mathrm{~V}$. Under the optimized conditions, the analytical performance of the present method is summarized in Table 1.

\section{Detection of Trace Amounts of Benzene, Toluene,} and Ethylbenzene in the Presence of High Concentrations of Organic Vapors

To test the robustness of the method, analysis was performed in the presence of high concentrations of organic interferents. As shown in Figure 1d, detection of benzene (125 ppb), toluene (150 ppb), and ethylbenzene $(210 \mathrm{ppb})$ was successful in the presence of $0.1 \%$ acetone and $500 \mathrm{ppb}$ of nicotine. The very intense peak at $\mathrm{m} / \mathrm{z}$ of 59 can be assigned to protonated acetone, and another interfering peak at $\mathrm{m} / \mathrm{z} 163$ corresponds to protonated nicotine. Three peaks corresponding to the analytes of interest, benzene, toluene, and ethylbenzene, can also be distinguished, with recoveries calcu-
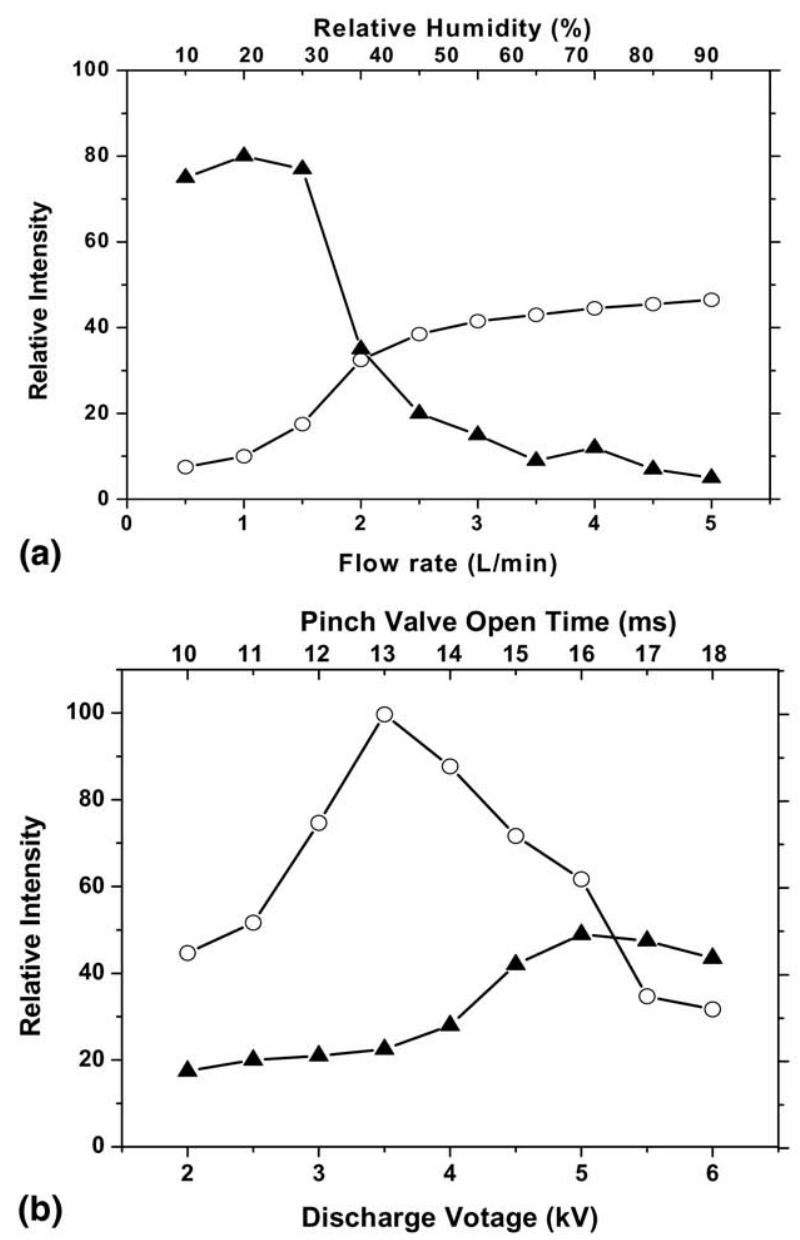

Figure 2. (a) Effect of relative humidity (filled triangle) and carrier gas flow rate $(\mathrm{O})$; $(\mathbf{b})$ effect of pinch valve open time $(\mathrm{O})$ and discharge voltage (filled triangle) on MS intensity of benzene signal at $m / z 78$. 
lated as $92 \%, 88 \%$, and $87 \%$, respectively. Considering the extreme conditions tested $(0.1 \%$ acetone and 500 ppb nicotine), the recoveries appear to be quite acceptable. There are two ways to further improve the performance of the present method; (1) use of internal standards for quantitation, and (2) use of tandem MS techniques. Since we are targeting a direct screening method for field analysis, the introduction of internal standards will increase the complexity of the operation, so internal standards were not used in this study. In this particular air monitoring application, simple mixtures are encountered, so it is possible to record only mass spectra; however, for more complex mixtures of analytes tandem MS is likely to be useful. It should also be noted that the response time is as low as $5 \mathrm{~s}$, and that the baseline recovers within $5 \mathrm{~s}$ when analyte is removed. After 1 month of testing at a sampling frequency of around 100 samples per day, the signal showed no sign of decreasing.

\section{Conclusion}

We have demonstrated the combination of APCI/Mini 10.5 as a powerful method for the direct analysis of trace compounds in the air. Benzene, toluene, and ethylbenzene were detected using typical APCI conditions as $m / z 78,91$, and 105, with LODs below 2 ppb and response times about $5 \mathrm{~s}$. Recoveries between $87 \%$ to $92 \%$ at the presence of high levels of acetone and nicotine imply that method can be directly used for screening environmental air. Other trace chemicals, such as DEET and DMMP, can also be directly detected with high sensitivity. This study illustrates the capabilities of miniature MS instruments in field analysis using simple sampling and ionization methods.

\section{Acknowledgments}

The authors acknowledge financial support from the Office of Naval Research, Research Tools Program (N00014-05-1-0454). They also thank Thermo-Fisher Scientific (Franklin, MA, USA) for providing some of the gas samples.

\section{Appendix A Supplementary material}

Supplementary material associated with this article may be found in the online version at doi:10.1016/ j.jasms.2009.09.018.

\section{References}

1. Rinsky, R. A.; Smith, A. B.; Hornung, R.; Filloon, T. G.; Young, R. J.; Okun, A. H.; Landrigan, P. J. Benzene and Leukemia-an Epidemiologic Risk Assessment. New Engl. J. Med. 1987, 316, 1044-1050.

2. Hayes, R. B.; Yin, S. N.; Dosemeci, M.; Li, G. L.; Wacholder, S.; Travis, L. B.; Li, C. Y.; Rothman, N.; Hoover, R. N.; Linet, M. S. Benzene and the Dose-Related Incidence of Hematologic Neoplasms in China. J. Natl. Cancer I 1997, 89, 1065-1071.

3. Lynge, E.; Andersen, A.; Nilsson, R.; Barlow, L.; Pukkala, E.; Nordlinder, R.; Boffetta, P.; Grandjean, P.; Heikkila, P.; Horte, L. G.; Jakobsson, R.; Lundberg, I.; Moen, B.; Partanen, T.; Riise, T. Risk of Cancer and Exposure to Gasoline Vapors. Am. J. Epidemiol. 1997, 145, 449-458.
4. Agency for Toxic Substances and Disease Registry, http://www.atsdr. cdc.gov, accessed July 2009.

5. http://www.atsdr.cdc.gov/toxprofiles/tp3-c1-b.pdf, accessed July 2009.

6. http://www.atsdr.cdc.gov/toxprofiles/tp3-c8.pdf, accessed July 2009.

7. Directive 2000/69/EC of the European Parliament and of the Council of 16 November 2000 Relating to Limit Values for Benzene and Carbon Monoxide in Ambient Air. Official Journal L131, 13/12/2000.

8. Hill, H. H.; Martin, S. J. Conventional Analytical Methods for Chemical Warfare Agents. Pure Appl. Chem. 2002, 74, 2281-2291.

9. Seto, Y.; Kanamori-Kataoka, M.; Tsuge, K.; Ohsawa, I.; Matsushita, K.; Sekiguchi, H.; Itoi, T.; Iura, K.; Sano, Y.; Yamashiro, S. Sensing Technology for Chemical Warfare Agents and Its Evaluation Using Authentic Agents. Sens. Actuators B, Chem. 2005, 108, 193-197.

10. Seto, Y.; Kanamori-Kataoka, M.; Tsuge, K.; Ohsawa, I.; Maruko, H.; Sekiguchi, H.; Sano, Y.; Yamashiro, S.; Matsushita, K.; Itoi, T.; Iura, K. Development of an On-Site Detection Method for Chemical and Biological Warfare Agents. Toxin. Rev. 2007, 26, 299-312.

11. Arthur, C. L.; Killam, L. M.; Buchholz, K. D.; Pawliszyn, J.; Berg, J. R. Automation and Optimization of Solid-Phase Microextraction. Anal. Chem. 1992, 64, 1960-1966.

12. Zhang, Z. Y.; Yang, M. J.; Pawliszyn, J. Solid-Phase Microextraction. Anal. Chem. 1994, 66, A844-A853.

13. Gorecki, T.; Pawliszyn, J. Effect of Sample Volume on Quantitative Analysis by Solid-Phase Microextraction. 1. Theoretical Considerations. Analyst 1997, 122, 1079-1086.

14. Gorecki, T.; Khaled, A.; Pawliszyn, J. The Effect of Sample Volume on Quantitative Analysis by Solid Phase Microextraction. 2. Experimental Verification. Analyst 1998, 123, 2819-2824.

15. Zhang, Z. Y.; Pawliszyn, J. Headspace Solid-Phase Microextraction. Anal. Chem. 1993, 65, 1843-1852.

16. Braida, W. J.; Pignatello, J. J.; Lu, Y. F.; Ravikovitch, P. I.; Neimark, A. V.; Xing, B. S. Sorption Hysteresis of Benzene in Charcoal Particles. Environ. Sci. Technol. 2003, 37, 409-417.

17. Liverman, D. M.; Wilson, J. P. The Mississauga Train Derailment and Evacuation, 10-16 November 1979. Canadian Geographer Geographe Canadien 1981, 25, 365-375.

18. Carroll, D. I.; Dzidic, I.; Stillwell, R. N.; Haegele, K. D.; Horning, E. C. Atmospheric Pressure Ionization Mass Spectrometry-Corona Discharge Ion Source for Use in Liquid Chromatograph Mass Spectrometer Computer Analytical System. Anal. Chem. 1975, 47, 2369-2373.

19. Carroll, D. I.; Dzidic, I.; Horning, M. G.; Montgomery, F. E.; Nowlin, J. G.; Stillwell, R. N.; Thenot, J. P.; Horning, E. C. Chemical Ionization Mass Spectrometry of Nonvolatile Organic Compounds. Anal. Chem. 1979, 51, 1858-1860.

20. Riter, L. S.; Laughlin, B. C.; Nikolaev, E.; Cooks, R. G. Direct Analysis of Volatile Organic Compounds in Human Breath using a Miniaturized Cylindrical Ion Trap Mass Spectrometer with a Membrane Inlet. Rapid Commun. Mass Spectrom. 2002, 16, 2370-2373.

21. Keil, A.; Hernandez-Soto, H.; Noll, R. J.; Fico, M.; Gao, L.; Ouyang, Z. Cooks, R. G. Monitoring of Toxic Compounds in Air Using a Handheld Rectilinear Ion Trap Mass Spectrometer. Anal. Chem. 2008, 80, 734-741.

22. Johnson, R. C.; Cooks, R. G.; Allen, T. M.; Cisper, M. E.; Hemberger P. H. Membrane Introduction. Mass Spectrometry: Trends and Applications. Mass Spectrom. Rev. 2000, 19, 1-37.

23. Alberici, R. M.; Zampronio, C. G.; Poppi, R. J.; Eberlin, M. N. Water Solubilization of Ethanol and BTEX from Gasoline: On-line Monitoring by Membrane Introduction Mass Spectrometry. Analyst 2002, 127, 230-234.

24. Janfelt, C.; Frandsen, H.; Lauritsen, F. R. Characterization of a MiniMembrane Inlet Mass Spectrometer for On-site Detection of Contaminants in Both Aqueous and Liquid Organic Samples. Rapid Commun. Mass Spectrom. 2006, 20, 1441-1446.

25. Frandsen, H.; Janfelt, C.; Lauritsen, F. R. Fast and Direct Screening of Polyaromatic Hydrocarbon (PAH)-Contaminated Sand Using a Miniaturized Membrane Inlet Mass Spectrometer (mini-MIMS). Rapid Commun. Mass Spectrom. 2007, 21, 1574-1578.

26. Sokol, E.; Edwards, K. E.; Qian, K.; Cooks, R. G. Rapid Hydrocarbon Analysis Using a Miniature Rectilinear Ion trap Mass Spectrometer. Analyst 2008, 133, 1064-1071.

27. Horning, E. C.; Horning, M. G.; Carroll, D. I.; Dzidic, I.; Stillwel, R. N. New Picogram Detection System Based on a Mass Spectrometer with an External Ionization Source at Atmospheric Pressure. Anal. Chem. 1973, $45,936-943$.

28. Sunner, J.; Nicol, G.; Kebarle, P. Factors Determining. Relative Sensitivity of Analytes in Positive Mode Atmospheric Pressure Ionization Mass Spectrometry. Anal. Chem. 1988, 60, 1300-1307.

29. Gao, L.; Song, Q. Y.; Patterson, G. E.; Cooks, R. G.; Ouyang, Z Handheld Rectilinear Ion Trap Mass Spectrometer. Anal. Chem. 2006, 78, 5994-6002.

30. Mulligan, C. C.; Justes, D. R.; Noll, R. J.; Sanders, N. L.; Laughlin, B. C.; Cooks, R. G. Direct Monitoring of Toxic Compounds in Air Using a Portable Mass Spectrometer. Analyst 2006, 131, 556-567.

31. Cotte-Rodriguez, I.; Justes, D. R.; Nanita, S. C.; Noll, R. J.; Mulligan, C. C.; Sanders, N. L.; Cooks, R. G. Analysis of Gaseous Toxic Industrial Compounds and Chemical Warfare Agent Simulants by Atmospheric Pressure Ionization Mass Spectrometry. Analyst 2006, 131, 579-589.

32. Carroll, D. I.; Dzidic, I.; Stillwell, R. N.; Horning, M. G.; Horning, E. C. Subpicogram Detection System for Gas Phase Analysis Based Upon Atmospheric Pressure Ionization (API) Mass Spectrometry. Anal. Chem. 1974, 46, 706-710. 